\title{
A Problem Structuring Method for Innovation Strategy: A Tentative DPSIR Approach
}

\author{
Yuting Qiu, Yiyang Fan
}

Business School, University of Shanghai for Science and Technology, Shanghai, China.

Email: yting.qiu@gmail.com, fyyqq@usst.edu.cn

Received June, 2013

\begin{abstract}
The rise of emerging markets is restructuring the global economic and social landscape. It requires a new paradigm of global innovation strategy to meet this challenge. After reviewing possible trends in today's world, it is suggested that the objective of innovation is to create an inclusive-and-sustainable future. To achieve this goal, this paper is concerned with the use of the Problem Structuring Methods (PSMs) which encourage the participation of all stakeholders involved in decision making and policy development. DPSIR (Drivers-Pressures-States-Impacts-Responses) framework, a particular PSMs, is employed to provide a systematic view in problem identification, analysis and solving in terms of multiple perspectives of stakeholders.
\end{abstract}

Keywords: PSMs; DPSIR; Innovation Strategy

\section{Introduction}

The rise of emerging markets is one of the most major contexts of our times. These trends can be interpreted as heralds of a dramatic restructuring of the global economic and social landscape in the future. As a result, complexities and dynamics will be perennial challenges to global players and policy-makers. To rise to these challenges, a future-scenario paradigm can help firms deeply understand the potential evolution and grapple with uncertainty and volatility.

First and foremost, it's worth revisiting the essence of innovation from a broader perspective. The economy is undergoing worldwide unbalanced development. The rich world is suffering from sluggish growth that the traditional advanced markets become over-saturated. In contrast, the emerging world is becoming a much more lucrative market with the rise of a prospective middle class. But an underlying reality is that huge gaps remain between advanced world and emerging world, for example GNI per capita (PPP) in U.S. $(\$ 48,820)$ vs. China $(\$ 8,390)$ [1]. In emerging markets, the mega consumers whose unmet demands are limited by purchasing power, are accounting for more than $70 \%$ of the global population. To tap these enormous potential groups, the role of innovation should be not only boosting economic growth but also be solving everyday problem, eradicating poverty and hunger, and helping people attain an inclusive-and-sustainable future.

The inclusive-and-sustainable growth is a complex term referring to combine economic growth with social needs which depend upon multiple perspectives of stakeholders in the problem context. To achieve this goal, it requires the problem structuring methods (PSMs) which involve the participation of all stakeholders in working out a satisfactory solution. This paper is concerned with the use of the DPSIR (Drivers-Pressures-States-Impacts-Responses) framework, a particular problem structuring approach, to broaden the perspectives of participants and cast new light on the potential innovation strategies and actions.

\section{Innovation Strategy and PSMs}

\subsection{The Complex Dynamics of Reality}

Today, corporations operate in a highly dynamic environment. The number of players is enormous, and freeexchanging information encourages competition. Forces such as technological change and the global re-balancing from developed to emerging markets have made the problems increasingly complex, the markets more volatile and the consumers more diversified. Within this particularly challenging context, the economic, social and nature forces should be regarded as co-evolving in recurrent interactions. And there is non-linear relationship among each part that changes in one set affect others disproportionately.

This hyper-turbulent environment becomes a prime candidate for developing innovative and unique solutions. 
Thus the role of innovation has expanded its traditional function as a spur to economic growth in the Age of Schumpeter. It calls for a higher flexibility and adaptability of innovation in line with different market requirements, namely, more inclusive and sustainable to deliver unique value proposition to consumers. And this challenge places an ever-greater premium on developing new strategy of global innovation.

\subsection{Why PSMs?}

A problem structuring method is recommended for comprehending the complex dynamics of the external reality. The PSMs, such as DPSIR framework, have flexibility to develop innovation strategy in light of complexity, manage changes within dynamic system, and balance the interests of multiple players [2]. And as a subset of the participative methods, the PSMs encourage the participation of all stakeholders involved in decision making to address complex issues [3]. It provides a systematic view to identify the inner strengths and weaknesses in the process of innovation strategy development, and offer a means of compatibility to meet various needs of stakeholders.

The traditional problem-solving frameworks frequently address particular problems under particular conditions, thus they have limited applicability. The PSM is also not a silver bullet for solving any problem. Instead, it is a flexible mechanism for shaping complex problems into a structured way to develop innovation solutions which can be useful in a wide range of situations, from individual to organizations to industries to nations. And there are five key reasons to employ PSMs to develop innovation strategy:

1) There is non-optimizing way to devise specific innovation solutions for the complex and hyper-competitive marketplace. It requires us to seek alternative solutions which are acceptable and measurable effective.

2) Concerning the non-linear relationship, there are conflicts and interconnections among each parts of system which are needed to clarify.

3) Multiple players should be treated as active subjects instead of passive objects. Also, there are multiple decision takers.

4) There are both trends from bottom-up and top-down that require facilitate two-way communication and planning.

5) The models should accept uncertainty. The decision and policy are not immutable. Everything in the future will be catalyst for their dynamic changes.

\subsection{The Process to Develop Innovation Strategy}

A. Identify specific issues

The success of innovation is judged by its contribution to the reality of external environment. Before seeking a solution, it's needed to identify the issues firstly.

- What aspects of the issue should be concerned in analysis and decision making? Which is the principal matter to tackle?

- How interactions happen within and across economic, social and organizational systems? Do they generate desirable or undesirable outcomes?

- What are the systematic enablers or constraints? How to facilitate the advantage factors and eliminate the disadvantages?

B. Define the system boundaries

Drawing the system's boundaries is to examine carefully what or who should be involved in and who will be affected by this system (referred to the process of boundary critique). The identity of issues makes a significant difference to the system boundary. The objectives and players concerned with the issues decide the breadth of participation. They also decide that the issues should be discuss in what level, such as the global or local scope, the industrial or organizational sphere.

C. Measure and balance the value

The focus of all the solutions will be solving conflicts of interests at last. Thus while establishing system boundary, it involves identifying conflicts and making a value judgment. It's a question of the depth of participation which associates with value claims.

- What are people's different perspectives on the issue, and which values and assumptions underpin these perspectives?

- What issues and stakeholders are important or peripheral? Whose values could actually be respected and whose interests will be served by particular decision making?

D. Choose DPSIR as PSMs

DPSIR framework enables us to better understand the complex and dynamic interactions of each parts in system. To solve the issues, it requires us to identify causality (in particular the State changes resulting from specific Drivers and Pressures), and capture the uncertain Impacts and Responses to change in a systemic way.

E. Call for participation

No one with the system can have complete knowledge. PSMs emphasize participation in the knowledge inspiration and structuring process with a focus on model building. And model built by a small group will be present to a wider group as stimulus for discussion.

Guidance on how this might best be brought about is somewhat limited and a broad range of interpretations will manifest in practice. That's the principle of PSMs embrace diversity in a diversity of forms.

\subsection{The Benefits and Risks}

A. Over simplification? 
Communication which is a main function which demands simplicity. Indicators within system always tend to simplify the complex reality for measurement and facilitating information exchange. But is it over simplification that some important factors or participants will be ignore or omit? Thus researches should pay great attention to the extent of simplification. Serve particular interests to make an acceptable decision or involve wider group in policy development? The major objective decides the level of simplicity.

B. Deal with uncertainty

PSMs can be viewed as heuristic devices to facilitate engagement, communication and knowledge inspiration. DPSIR in particular, aims to develop a framework to represent a shared understanding of reality. The controversial or even competing perspectives of stakeholders will be accommodated in the process of model building. The uncertainty and complexity will be downplayed by DPSIR framework [4].

C. The resilience

Resilience is measured by the magnitude of turbulence that can be absorbed before the system changes its structure[5]. PSMs are unformulated frameworks with dynamic changes under different context. Their great resilience to changes comes from the general inclusion of multiple attitudes, and value delivery across various groups of stakeholders.

D. The ability of re-balancing

PSMs pay a higher degree of focus on the ability of re-balancing. Ackermann (2012) highlights that PSMs should respect not only who to involve but also who to manage when considering outcomes [6]. The framework offers a systematic communication that multiple value claims would be considered by the participants in balance. But this is not imposed on the participants but comes from their own understanding and discourse.

\section{DPSIR as a PSMs for Innovation Strategy}

\subsection{DPSIR Background}

The DPSIR framework was developed by the European Environmental Agency and acts as a form of typology to help policy-makers grab the relevance and meaning of the indicators [7]. Constructing a preliminary conceptual model, DPSIR can be used as a means for structuring and analyzing, even a model for decision support [8].

\subsection{Indicators Definition}

DPSIR consists of five pre-determined indicators Driving forces, Pressures, State changes, Impacts and Responses. Each indicator is used to measure some feature of the context which is important to the participants.

- Driving forces - The drivers come from changes in economic and social development. The essential to find out the driving forces is to encourage participants to express how changes happened in their context.

- Pressures - Each of Drivers exert potential Pressure on the system. Pressures on the system can be locally/regionally/internationally endogenic pressures or exogenic pressures. In terms of innovation strategy development, the pressure is mostly exogenic because the complex dynamics of reality.

- State changes - State of the external reality changes in the background status.

- Impacts - State changes lead to actual or potential Impacts on society, namely welfare changes. The understanding of socio-economic drivers or pressures should be broadened and pay adequate attention not only to the state of background, but also to the state of social matters.

- Responses - Societal Responses feed back on the Driving forces and Pressures through adaptation or disruptive action. They come from the requirement to mitigate or overcome the problems created by State changes or Impacts.

Smeets and Weterings(1999) [7]point out three major purpose of indicators in terms of problem structuring:

1) To supply information on problems, in order to enable players to weigh pros and cons;

2) To support strategy development by identifying key factors that cause pressure on the external environment;

3) To monitor the effects of responses.

\subsection{Objectives of Innovation Strategy}

As the global economy's center of gravity shifts, the emerging countries have been the world's fastest-growing economies while the advanced countries slow their tempo of growth with the risk of sinking into a prolonged slump. Responsible for this trend are socio-demographic changes, the search for differentiation in saturated markets, shifts in purchasing power, the internationalization of markets and product development, and the trend towards diversification. Accordingly, the objectives of global innovation strategy should be accessibility, acceptability, affordability and sustainability (Table 1).

Table 1. Objectives of innovation strategy.

\begin{tabular}{ccc}
\hline Objectives & \multicolumn{1}{c}{ Key point } & \multicolumn{1}{c}{ Issues to tackle } \\
\hline Accessibility & $\begin{array}{c}\text { Redefine how products } \\
\text { distribute and sell }\end{array}$ & $\begin{array}{l}\text { Tackle the issues of market } \\
\text { fragmentation to reach a wide } \\
\text { range of consumers }\end{array}$ \\
Acceptability & Socially desirable & $\begin{array}{l}\text { Create and deliver value to } \\
\text { tackle the issue of demand } \\
\text { heterogeneity }\end{array}$ \\
Affordability & price-performance ratio & $\begin{array}{l}\text { Use feasible technology and } \\
\text { control at a reasonable cost to } \\
\text { fulfill unmet demands } \\
\text { Maintain a balanced and } \\
\text { long-lasting development [9] }\end{array}$ \\
\hline
\end{tabular}




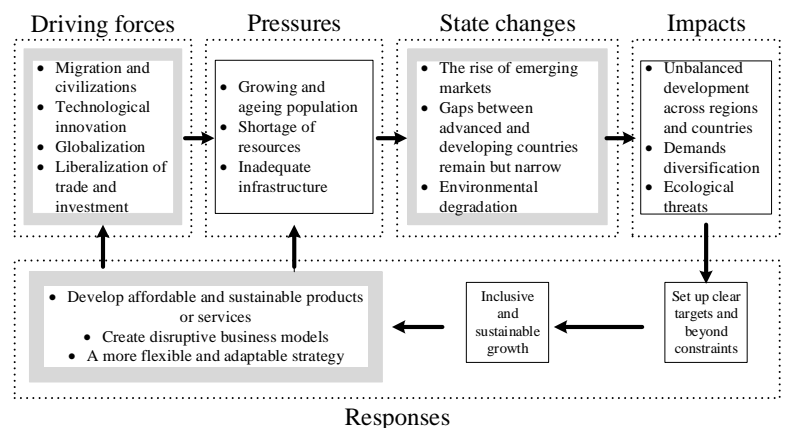

Figure 1. DPSIR model for innovation strategy.

\subsection{DPSIR Model for Innovation Strategy}

After reviewing the complex dynamics of reality, this paper develops a tentative DPSIR model (Figure 1) to assess the interactions of indicators to achieve today's objective of innovation.

\section{Discussion and Conclusions}

The PSMs can be used not only in general but also specific context. DPSIR framework, a particular PSMs, is a cyclical model which can be employed for recurrent review to meet the complex and dynamic nature of innovation. Involving multiple perspectives of stakeholders, DPSIR provides a systematic view in problem identification, analysis and solving. But DPSIR framework is fundamentally an expert device to be interpreted by specialists for the application of policy makers. Could DPSIR be 'handed over' to players in system as a means to self - assess model? It requires more discussion and practical cases to extend the application of DPSIR as a PSM - offering technical methods and stakeholder engagement.

\section{Acknowledgements}

Financial support from NSSFC (NSSFC/13BJY021) and Academic Talent Development Program for Liberal Arts and Social Sciences, Shanghai Academic Degrees Committee (2012[13]) is gratefully acknowledged. The research has also benefited from the support of China Shanghai Municipal Research Project of Education and
Science 2011(B11041) and is also part of the Soft Science Research Program of the Shanghai Foundation for Development of Science and Technology, China (096921048).

\section{REFERENCES}

[1] World Bank, “WDI World Development Indicators,” GNI per Capita Ranking, Atlas Method and PPP Based, Available at: http://data.worldbank.org/data-catalog/GNI-per-capita-Atl as-and-PPP-table, Dec. 21, 2012.

[2] S. Bell, "DPSIR= a Problem Structuring Method? An Exploration from the "Imagine" Approach," European Journal of Operational Research, Vol. 222, No. 2, 2012, pp. 350-360.

[3] Midgley, Gerald, et al., "Towards a New Framework for Evaluating Systemic Problem Structuring Methods," European Journal of Operational Research, Vol. 229, No. 1, 2013, pp. 143-154

[4] Maxim, Laura, J. H. Spangenberg and Martin O'Connor, "An Analysis of Risks for Biodiversity under the DPSIR Framework,” Ecological Economics, Vol. 69, No. 1, 2009, pp. 12-23.

[5] C. Holling and L. Gunderson, "Resilience and Adaptive Cycles. Panarchy: Understanding Transformations in Human and Natural Systems,” L. Gunderson and C. Holling, New York, Island Books, 2002.

[6] F. Ackermann, "Problem Structuring Methods 'in the Dock': Arguing the Case for Soft OR,” European Journal of Operational Research, Vol. 219, No. 3, 2013, pp. 652-658. doi:10.1016/j.ejor.2011.11.014

[7] E. Smeets and R. Weterings, "Environmental Indicators: Typology and Overview,” European Environment Agency, Copenhagen, 1999.

[8] Gregory, Amanda, et al., “A Problem Structuring Method for Ecosystem-based Management: The DPSIR Modelling Process," European Journal of Operational Research, Vol. 227, No. 3, 2013, pp. 558-569. doi:10.1016/j.ejor.2012.11.020

[9] Foxon, J. Timothy, et al., "Towards a New Complexity Economics for Sustainability," Cambridge Journal of Economics, Vol. 37, No. 1, 2013, pp. 187-208. doi:10.1093/cje/bes057 